\title{
Importance of Aerosol Optical Depth in the Atmospheric Correction of Ocean Colour Remote Sensing Data
}

\author{
Sriperambudur Udaya Laxmi' ${ }^{1}$, Sonnati Chandralingam², Pullaiahgari Venkata Nagamani3, \\ Inaganti Veera Ganga Bhavani ${ }^{3}$, Yerramsetti Umamaheswara Rao ${ }^{3}$
}

${ }^{1}$ Department of Physics, KMIT, Hyderabad, India

${ }^{2}$ Department of Physics, JNTU, Hyderabad, India

${ }^{3}$ OSG/ECSA, National Remote Sensing Centre, Hyderabad, India

Email:pvnagamani@gmail.com

How to cite this paper: Laxmi, S.U., Chandralingam, S., Nagamani, P.V., Bhavani, I.V.G. and Rao, Y.U. (2017) Importance of Aerosol Optical Depth in the Atmospheric Correction of Ocean Colour Remote Sensing Data. Open Journal of Marine Science, 7, 100-108.

http://dx.doi.org/10.4236/ojms.2017.71008

Received: July 13, 2016

Accepted: January 8, 2017

Published: January 11, 2017

Copyright (c) 2017 by authors and Scientific Research Publishing Inc. This work is licensed under the Creative Commons Attribution International License (CC BY 4.0).

http://creativecommons.org/licenses/by/4.0/

\begin{abstract}
Atmospheric aerosols being an important component of the atmosphere play an important role in global and regional climate change. Aerosols can affect air quality, climate change and human health and have a significant effect on the solar energy budget. To study their quantitative effect is a challenging task due to their high spatial and temporal variability. This parameter represents one of the extinction coefficients of solar radiation and rate of suspended particles in the atmosphere. Ocean Colour Remote Sensing provides information about the four major geophysical parameters like chlorophyll and total suspended sediment concentration, vertical diffuse attenuation co-efficient and the aerosol optical thickness measured at $865 \mathrm{~nm}$. Aerosol optical depth $\tau^{\text {aer }}(\lambda)$ can be expressed as function of wavelength through Angstrom's equation $\left(\tau^{\text {aer }}=\beta \lambda^{-\alpha}\right)$, where " $\alpha$ ” and " $\beta$ " are known as Angstrom parameters. The Angstrom exponent, " $\alpha$ " is related to the size distribution of the aerosol particles and " $\beta$ " represents the amount of aerosols present in the atmosphere. In this present study, an attempt is made to study the impact of these two parameters by changing values from 0 to 0.05 for " $\alpha$ " and from 0.0 to 0.6 for " $\beta$ " in SeaDAS processing for estimating the aerosol optical depth. From this study, it is clear that for most of the applications either in the coastal or open ocean waters, alpha value varies from 0.0 to 0.3 over the north Indian Ocean. However, this has been further evaluated by various combinations for retrieving the AOD using OCM-2 data.
\end{abstract}

\section{Keywords}

Aerosol Optical Depth, SeaDAS, North Indian Ocean, OCM-2 


\section{Introduction}

The atmosphere is an important conduit for the carriage of particulate matter from the continents to the oceans. Aerosols play an important role in climate forcing and biogeochemical cycling. The presence of these wind-borne fluxes has a significant effect on physical, chemical and biological processes in the oceans. Oceanic aerosol is one of the major natural aerosol schemes and represents a significant role in the earth's radiative budget. Aerosols perform a precarious role in water vapour nucleation processes. Aerosols can influence the accumulation and size distribution of cloud droplets, which in turn can change effectively the radiative effects of clouds. The importance of aerosols in cloud processes also affects the flora and distribution of rainfall and ensuing distribution of clouds. The function of aerosols in climate forcing has great impact, because of the many undetermined facts about the various fundamental properties of aerosols and their temporal and spatial variability; only very primitive estimates could be made. In general, the significance of aerosol remote sensing covers two features: the climate of aerosols and their influence on atmosphere.

Aerosols are generated by a variety of natural as well as anthropogenic sources, and get allocated in the atmosphere through disordered mixing and transport which result in a large variability in their size distribution [1] [2] [3] [4]. At global stage, the natural sources (e.g., volcanic explosion, transfer of desert dust, etc.) of aerosols are existing over the anthropogenic sources (e.g., biomass burning, vehicular emission, etc.), but at regional areas the involvement of anthropogenic sources of aerosol is significant [5]. The long-range carrying of desert dust also contributes to the Aerosol Size Distribution (ASD) [4] [6] [7] [8]. The study on aerosol transport carried out by [9] [10] [11] [12] at Mohal in the northwestern region of the Indian Himalaya infers that this region gets influenced by dust aerosols due to its transport from the western deserts. The comprehension of the variability in the ASD is the main concern to measure the radiative effect of aerosol, but it is a difficult task due to insufficient information [13].

The aerosol optical depth spectrum (AOD, $\tau \beta \lambda)$ includes information pertaining to ASD and is used to compute Ångström exponent ( $\alpha$ ) and turbidity coefficient $(\beta)$ using Ångström Power Law [4] [7] [14]-[21]. Ångström exponent is a quantitative indicator of the ASD and the turbidity factor is a measure of total aerosol loading in a vertical column [4] [7] [14] [19] [21]. In general, Ångström Power Law is valid to the complete wavelength spectrum, only if the ASD fits to the Junge Power Law [4]. But, when the spectral range is extended and the ASD is generally multi-modal, it can introduce significant faults [19].

Therefore, the use of Ångström Power Law is not applicable to all the environments and regions [3] [4] [15] [16] [17] [22] [23]. When the wavelength range is extended, Ångström Power Law departs from its linear behavior of $\ln \tau \beta \lambda$ versus $\ln \lambda$ and this results in different values of $\alpha$ for different wavelength ranges [4]. This directs to a curvature in $\tau \beta \lambda$ which contains useful information about the ASD [3]. The value of $\alpha \leq 1$ shows that the size distributions are controlled by coarse mode aerosols such as dust or sea salt. The value of $\alpha \geq 2$ infers that the size distributions are dominated by fine mode aerosols that are generally attributed to anthropogenic activities [3] [14].

In view of the above discussed scientific rationale of ASD, the role of "alpha" and 
"beta", an attempt is made to study the range of these values and the effect of these two parameters in AOD retrieval has been studied using Oceansat-2 Ocean Colour Monitor.

\section{Study Area}

The present study has been carried out over tropical North Indian Ocean which imparts an ideal and exceptional natural laboratory to distinguish and understand the importance of aerosols in climate forcing. The present study is limited to the Open Ocean and coastal waters of the north Indian Ocean. The specific features that differentiate the North Indian Ocean (NIO) from other oceanic areas fundamentally arise from its unusual geographical settings and upper ocean circulation due to monsoon. The most prominent difference is the seasonal reversal of the monsoon winds and their influence on the ocean currents.

North Indian Ocean is subjected to aerosol radiative forcing causing from seasonally retrogressive southwest and northeast monsoon winds. The mutual effect of natural and anthropogenic aerosols could add to atmospheric and ecological imbalances in the eastern Arabian Sea. This emphasizes the need for a synoptic understanding of the atmosphere over the NIO, including the Angstrom turbidity parameter (b), aerosol-size distribution parameter $(\alpha)$, and subsequently aerosol optical thickness (AOT), a quantity parameter required for determining aerosol radiative forcing. The AOT over oceanic and coastal regions of the north Indian Ocean at $40^{\circ} \mathrm{E}, 110^{\circ} \mathrm{N}, 0^{\circ} \mathrm{W}$ and $35^{\circ} \mathrm{S}$ was studied and the study area is shown in Figure 1.

\section{Methodology}

Ångström (1961) proposed an empirical formula to approximate the spectral dependence of atmospheric extinction caused by aerosols. Spectral AOD contains information pertaining to size distribution used to compute $\alpha$ and $\beta$ using empirical formula which is famously known as the Ångström Power Law [24]. According to [24], the spectral

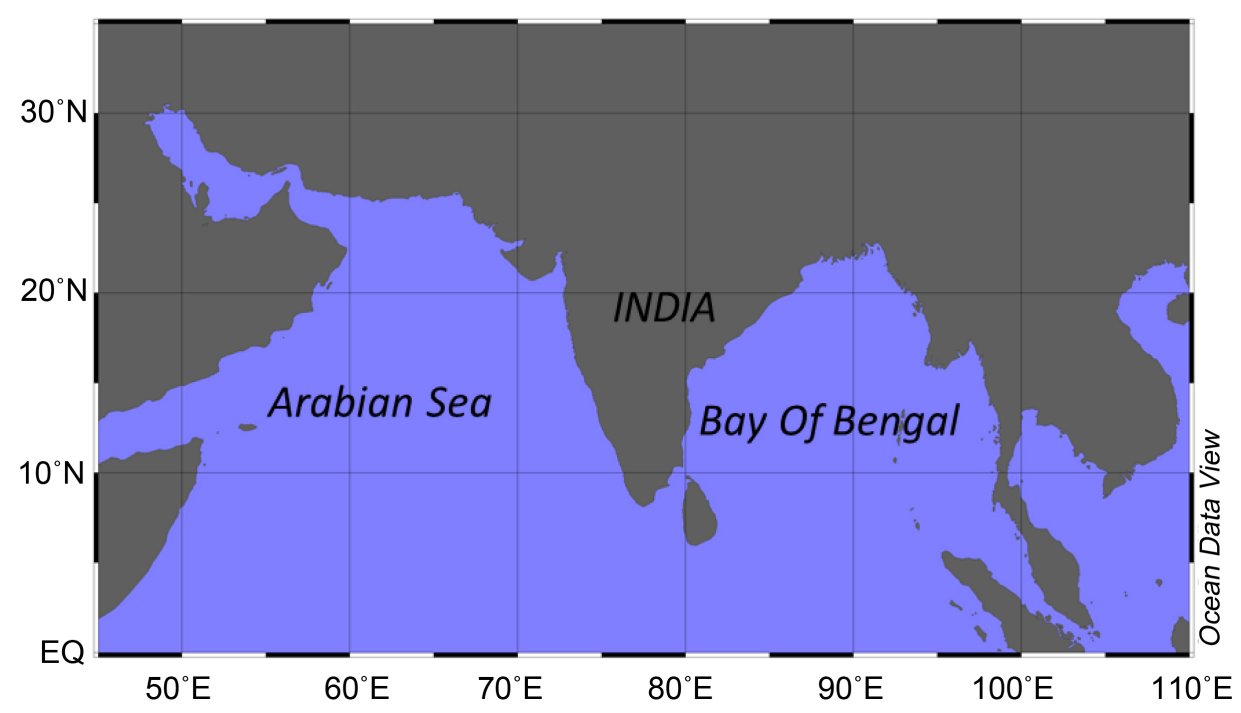

Figure 1. Geographical boundaries of the study area covering the north Indian Ocean. 
variation of AOT is denoted as

$$
\tau_{\alpha}(\lambda)=\beta(\lambda)^{-\alpha}
$$

The logarithmic scale of Equation (1) yields a straight line as:

$$
\ln \tau p \lambda=\ln \beta-\alpha \ln \lambda .
$$

where $\tau_{\alpha}(\lambda)$ is the AOT, $\beta$ often referred to as the Angstrom opaque parameter represents the $\mathrm{AOT}$ at the reference wavelength (i.e. $\lambda=1$ ), which may be considered as an indicator of total aerosols present in the atmosphere, and $\alpha$ is the Angstrom coefficient, which based on the size distribution of the aerosol. The plots of $\ln \tau p \lambda$ versus $\ln \lambda$, yield a straight line of slope $-\alpha$ and intercept $\ln \beta$. The validity of the Ångström Power Law is stated after Junge Power Law [25] for a limited range of particles, where significant extinction takes place and the spectral variation of the refractive index does not impose any significant variations on the Mie extinction factor [16]. Each spectral measurement of AOT was fitted to Equation (1) using linear least-squares fitting of log reorganized data to obtain $\alpha$ and $\log \beta$ as the slope of the fixed line and as the intercept, minimum and maximum values of $\alpha$ indicates coarse and fine aerosol particle sizes, respectively.

\section{OCM Characteristics and Data Processing}

Ocean Color Monitor-2 (OCM2) is an eight band radiometer onboard Oceansat-2 satellite for global ocean color measurements. OCM2 was launched on September 23, 2009 with six visible and two near infrared (NIR), centred at 412, 443, 490, 510, 555, 670, 765 and $865 \mathrm{~nm}$. The first six channels are used for investigating the ocean-colour constituents in the water column and the remaining two for measuring path reflectance i.e., aerosol and Rayleigh radiances to apply atmospheric correction for ocean colour analysis. The global ocean colour data processing package namely "SeaDAS" has been used for processing the $\mathrm{L} 1 \mathrm{~B}$ radiances of OCM-2 to generate the AOD product and the other ocean colour data products.

\section{Results and Discussion}

The spatial variations of satellite derived AOD during the months January-December explains the seasonal variability over study area. AOD is considerably increasing in the months of January to August than in the post monsoon season. The monthly mean AOD values of year 2014 at $865 \mathrm{~nm}$ wavelength of observations were mostly in the range from 0.2 to 0.5 by varying the Angstrom exponent and size distribution from 0.0 to 0.05 and 0.0 to 0.6 . The extent variation of AOD gives information on the particle size distribution in the total atmospheric column. The significance of " $\alpha$ " depends on the measure of the concentration of large to small aerosol particles and is associated in such a manner that higher value of $\alpha$ indicates influence of smaller particles. The total aerosol loading is represented by " $\beta$ " in the atmosphere and as such higher values of " $\beta$ " give an evidence of poor visibility due to higher turbidity level. The seasonal variability of AOD over the north Indian Ocean, Arabian Sea and Bay of Bengal are shown in Figures 2-4 respectively with mean median and sigma parameters. From the study mean value of over the coastal region $(\sim 1.24)$ is found to be larger as compared to that 
over the open ocean $(\sim 0.2-0.8)$. The larger values of Angstrom exponent $(\alpha)$ can also be allocated to the higher fine-mode aerosol loading near to the coast, arising mainly

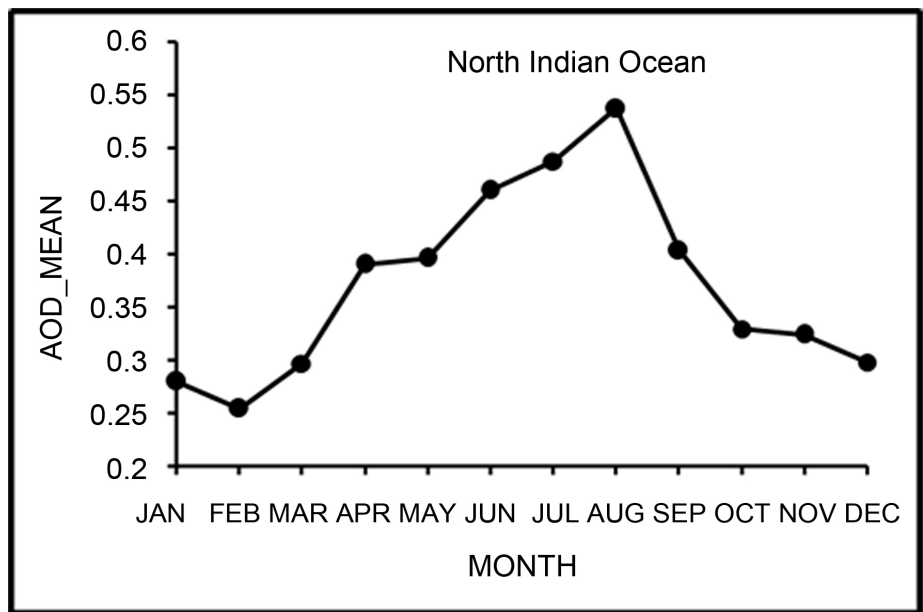

Figure 2. Seasonal variability of aerosol optical depth over the north Indian Ocean.

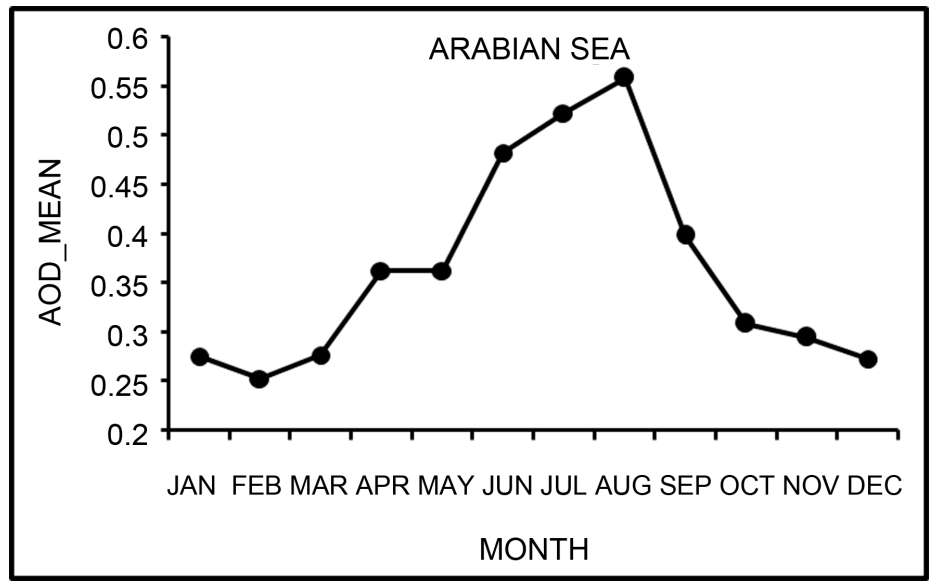

Figure 3. Seasonal variability of aerosol optical depth over the Arabian Sea for the year 2014 .

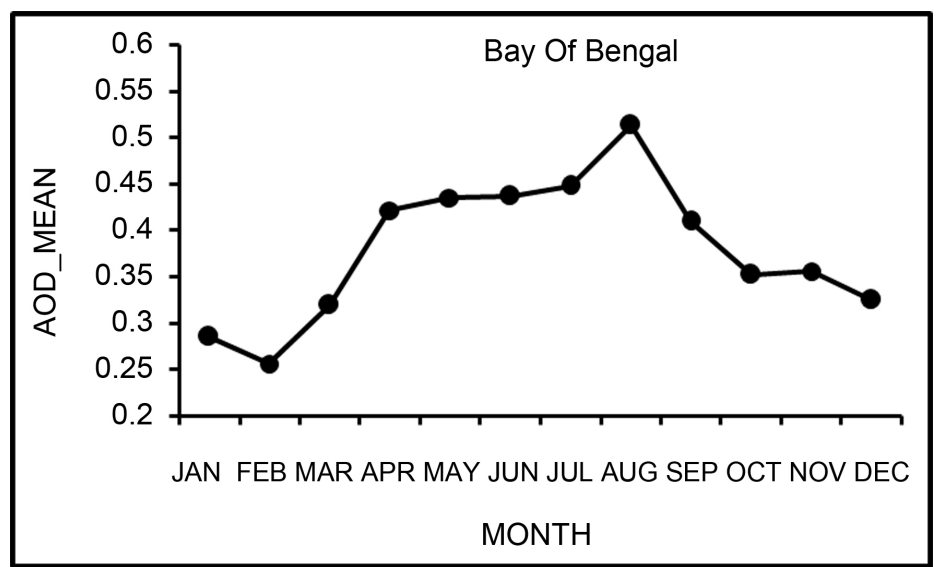

Figure 4. Seasonal variability of aerosol optical depth over the Bay of Bengal for the year 2014. 
from the anthropogenic activities. The second derivative of Alpha comprises a measure of the rate of change of the slope with respect to wavelength.

\section{Conclusions}

The daily average (mean \pm standard deviation; $0.3 \pm 0.11$ ) AOD at $865 \mathrm{~nm}$ of OCM-2 sensor for the entire study period is obtained as $0.33 \pm 0.08,0.10,0.07$. The seasonal highest AOD at $865 \mathrm{~nm}$ in pre-monsoon is obtained as $0.55 \pm 0.13$. This is due to enhanced loading of dust aerosols, which are transported from the desert regions (e.g., Thar Desert, etc.) [9] [10] [11] [12] over the Arabian Sea. The seasonal lowest AOD is obtained as $0.27 \pm 0.07$ in winter, whereas $0.09 \pm 0.03$ in post monsoon. The spatial distribution of AOD over the north Indian Ocean, Arabian Sea and Bay of Bengal for the year 2014 is shown in Figures 5-7 respectively derived from Oceansat-2 OCM with 360 $\mathrm{m}$ spatial resolution.

The seasonal variation in " $\alpha$ " and " $\beta$ ' averaged over a period of one year from January 2014 to December 2014 is estimated from the linear fit of spectral AOD at $865 \mathrm{~nm}$, shown in Figure 2 for the North Indian Ocean. From the analysis, it is known that during pre-monsoon, large AOD values are associated with small " $\alpha$ " value. This indicates that the relative concentration of coarse mode aerosols is higher than fine mode aerosols. During post-monsoon, small AOD values are associated with large " $\alpha$ " values. This indicates that during post-monsoon, the contribution of fine mode aerosols in the atmosphere is relatively more than coarse mode aerosols.

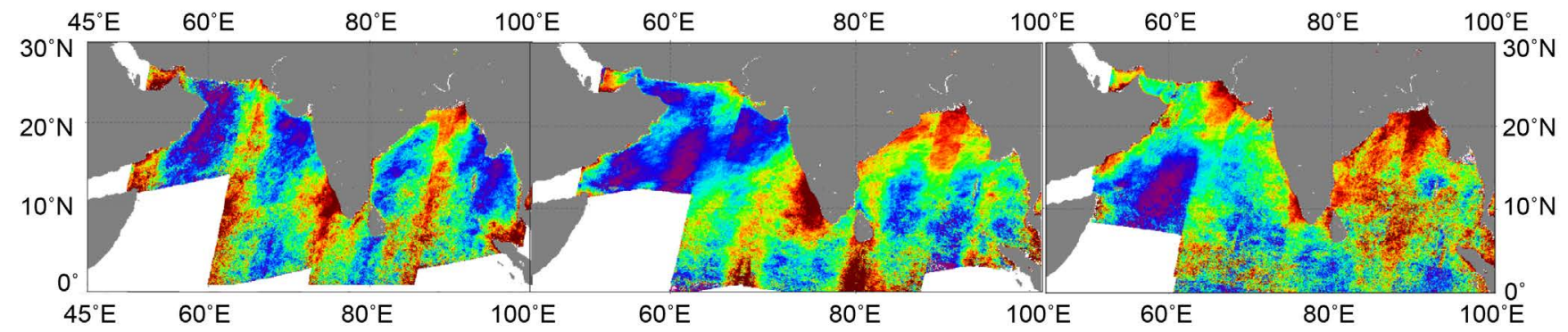

Figure 5. Monthly AOD variation over north Indian ocean for the year 2014.

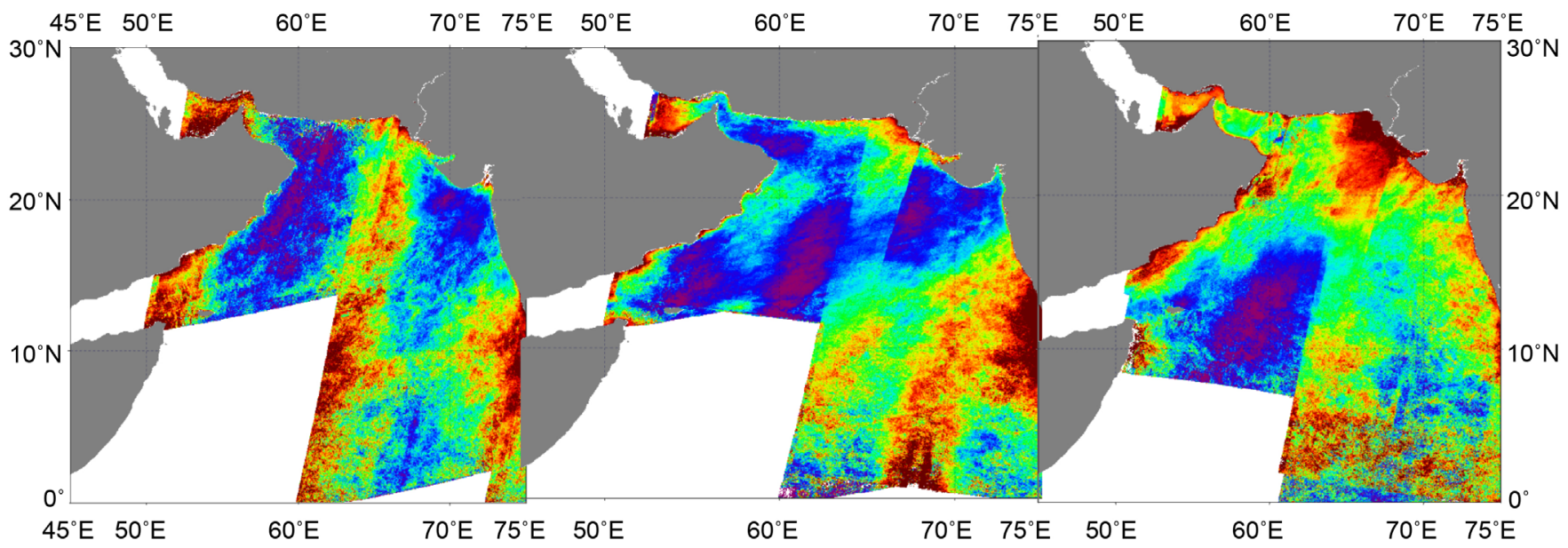

Figure 6. Seasonal variability of AOD over the Arabian Sea derived from OCM-2 for the year 2014. 


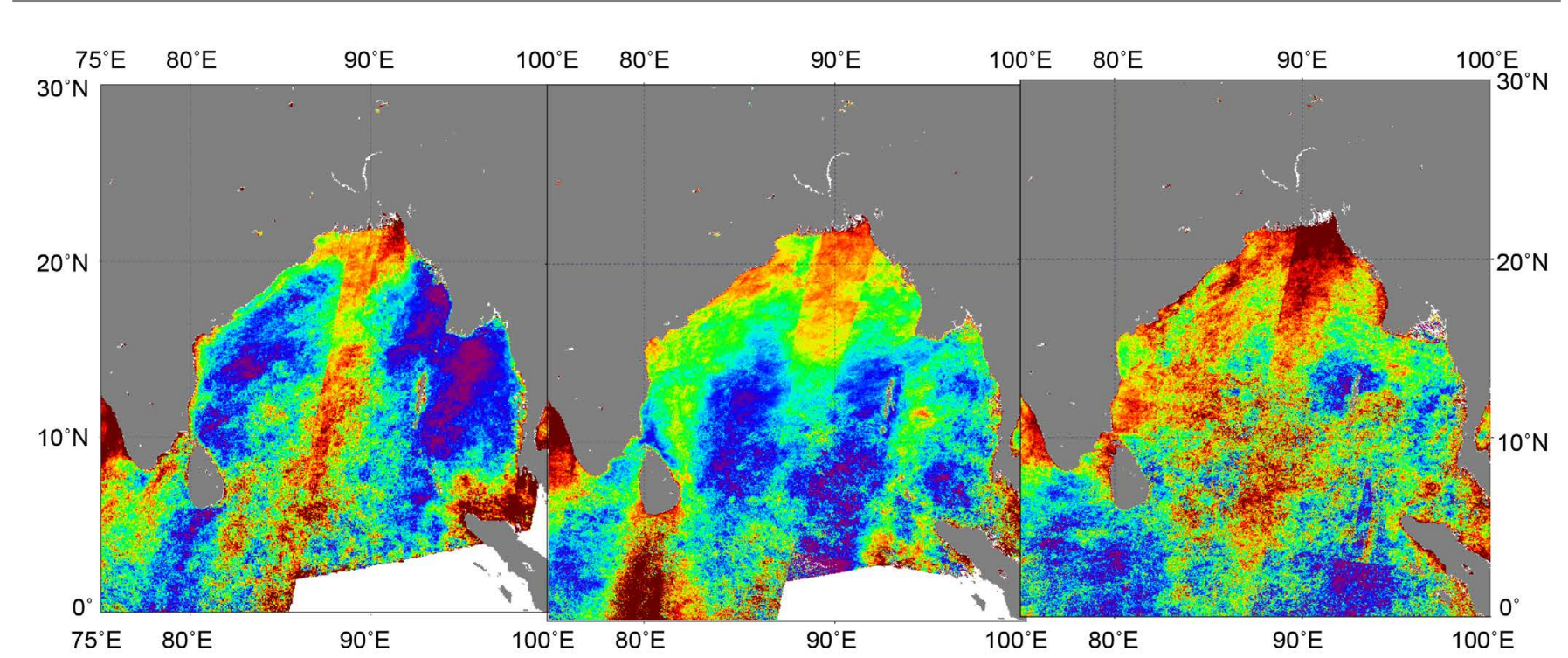

Figure 7. Seasonal variability of AOD over the Bay of Bengal derived from OCM-2 for the year 2014.

AOD over the Arabian Sea is affected by the transport of dust aerosols from the plains of Pakistan and Thar Sahara deserts. This could be one of the major causes for the accumulation of more fine aerosols over the Arabian Sea. The daily average values of " $\alpha$ " and " $\beta$ " for the entire study period are obtained as $0.37 \pm 0.41$ and $0.12 \pm 0.067$, respectively.

\section{Acknowledgements}

We are thankful to the internet based interface for the visualization and analysis of the OCM2 data. Thanks to ocean science department, NRSC for their immense contribution for data availability.

\section{References}

[1] Meszaros, E. (1981) Atmospheric Chemistry Fundamental Aspects. Elsevier Scientific Publishing Company, New York.

[2] Reist, P.C. (1984) Introduction to Aerosol Science. Macmillan Publishing Company, New York.

[3] Eck, T.F., Holben, B.N., Reid, J.S., Dubovik, O., Smirnov, A., O’Neill, N.T., Slutsker, I. and Kinne, S. (1999) Wavelength Dependence of the Optical Depth of Biomass Burning, Urban, and Desert Dust Aerosols. Journal of Geophysical Research, 104, 31333-31349. https://doi.org/10.1029/1999jd900923

[4] Kedia, S. and Ramachandran, S. (2009) Variability in Aerosol Optical and Physical Characteristics over the Bay of Bengal and the Arabian Sea Deduced from Ångström Exponents. Journal of Geophysical Research, 114, D14207. https://doi.org/10.1029/2009JD011950

[5] Ramanathan, V., et al. (2001) Indian Ocean Experiment: An Integrated Analysis of the Climate Orcing and Effects of the Great Indo-Asian Haze. Journal of Geophysical Research, 106, 28371-28398. https://doi.org/10.1029/2001jd900133

[6] Moorthy, K.K. and Satheesh, S.K. (2000) Characteristics of Aerosols over a Remote Island, Minicoy in the Arabian Sea: Optical Properties and Retrieved Size Characteristics. Quarterly Journal of the Royal Meteorological Society, 126, 81-109. https://doi.org/10.1002/qj.49712656205 
[7] Gogoi, M.M., Bhuyan, P.K. and Moorthy, K.K. (2008) Estimation of the Effect of LongRange Transport on Seasonal Variation of Aerosols over Northeastern India. Annales Geophysicae, 26, 1365-1377. https://doi.org/10.5194/angeo-26-1365-2008

[8] Kedia, S. and Ramachandran, S. (2010) Seasonal Variations in Aerosol Characteristics over an Urban Location and a Remote Site in Western India. Atmospheric Environment, 45, 2120-2128. https://doi.org/10.1016/j.atmosenv.2011.01.040

[9] Kuniyal, J.C., Thakur, A., Thakur, H.K., Sharma, S., Pant, P., Rawat, P.S. and Moorthy, K.K. (2009) Aerosol Optical Depths at Mohal-Kullu in the Northwestern Indian Himalayan High Altitude Station during ICARB. Journal of Earth System Science, 118, 41-48. https://doi.org/10.1007/s12040-009-0004-y

[10] Guleria, R.P., Kuniyal, J.C., Rawat, P.S., Thakur, H.K., Sharma, M., Sharma, N.L., Singh, M., Chand, K., Sharma, P., Thakur, A.K., Dhyani, P.P. and Bhuyan, P.K. (2011) Aerosols Optical Properties in Dynamic Atmosphere in the Northwestern Part of the Indian Himalaya: A Comparative Study from Ground and Satellite Based Observations. Atmospheric Research, 101, 726-738. https://doi.org/10.1016/j.atmosres.2011.04.018

[11] Guleria, R.P., Kuniyal, J.C., Rawat, P.S., Sharma, N.L., Thakur, H.K., Dhyani, P.P. and Singh, M. (2011) The Assessment of Aerosol Optical Properties over Mohal in the Northwestern Indian Himalaya Using Satellite and Ground Based Measurements and an Influence of Aerosol Transport on Aerosol Radiative Forcing. Meteorology and Atmospheric Physics, 113, 153-169. https://doi.org/10.1007/s00703-011-0149-5

[12] Guleria, R.P., Kuniyal, J.C., Rawat, P.S., Thakur, H.K., Sharma, M., Sharma, N.L., Dhyani, P.P. and Singh, M. (2012) Validation of MODIS Retrieval Aerosol Optical Depth and an Investigation on Aerosol Transport over Mohal in the Northwestern Indian Himalaya. International Journal of Remote Sensing, 33, 5379-5401. https://doi.org/10.1080/01431161.2012.657374

[13] IPCC (2007) Climate Change 2007: The Physical Science Basis. Cambridge University Press, Cambridge.

[14] Schuster, G.L., Dubovik, O. and Holben, B.N. (2006) Ångström Exponent and Bimodal Aerosol Size Distributions. Journal of Geophysical Research, 111, D07207. https://doi.org/10.1029/2005JD006328

[15] Kaskaoutis, D.G. and Kambezidis H.D. (2006) Investigation on the Wavelength Dependence of the Aerosol Optical Depth in the Athens Area. Quarterly Journal of the Royal Meteorological Society, 132, 2217-2234. https://doi.org/10.1256/qj.05.183

[16] Kaskaoutis, D.G., Kambezidis, H.D., Adamopoulos, A.D. and Kassomenos P.A. (2006) Comparison between Experimental Data and Modeling Estimates of Atmospheric Optical Depth over Athens, Greece. Journal of Atmospheric and Solar-Terrestrial Physics, 68, 11671178. https://doi.org/10.1016/j.jastp.2006.02.011

[17] Kaskaoutis, DG., Kambezidis, H.D., Hatzianastassiou, N., Kosmopoulos P.G. and Badarinath K.V.S. (2007) Aerosol Climatology: Dependence of the Ångström Exponent on Wavelength over Four AERONET Sites. Atmospheric Chemistry and Physics, 7, 7347-7397. https://doi.org/10.5194/acpd-7-7347-2007

[18] Kaskaoutis, D.G., Badarinath, K.V.S., Kharol, S.K., Sharma, A.R. and Kambezidis, H.D. (2009) Variations in the Aerosol Optical Properties and Types over the Tropical Urban Site of Hyderabad, India. Journal of Geophysical Research, 114, D22204. https://doi.org/10.1029/2009JD012423

[19] Kaskaoutis, D.G., Kalapureddy, M.C.R., Moorthy, K.K., Devara P.C.S., Nastos, P.T., Kosmopoulos, P.G. and Kambezidis, H.D. (2010) Heterogeneity in Pre-Monsoon Aerosol Types over the Arabian Sea Deduced from Ship-Borne Measurements of Spectral AODs. Atmospheric Chemistry and Physics, 10, 4893-4908.

https://doi.org/10.5194/acp-10-4893-2010 
[20] Sharma, A.R., Kharol, S.K., Badarinath, K.V.S. and Singh, D. (2010) Impact of Agriculture Crop Residue Burning on Atmospheric Aerosol Loading-A Study over Punjab State, India. Annals of Geophysics, 28, 367-379. https://doi.org/10.5194/angeo-28-367-2010

[21] Sharma, N.L., Kuniyal, J.C., Singh, M., Sharma, M. and Guleria, R.P. (2011) Characteristics of Aerosol Optical Depth and Ångström Parameters over Mohal in the Kullu Valley of Northwest Himalayan Region, India. Acta Geophysica, 59, 334-360. https://doi.org/10.2478/s11600-010-0046-1

[22] Reid, J.S., Eck, T.F., Christopher, S.A., Hobbs, P.V. and Holben, B.N. (1999) Use of the Ångström Exponent to Estimate the Variability of Optical and Physical Properties of Aging Smoke Particles in Brazil. Journal of Geophysical Research, 104, 27473-27489. https://doi.org/10.1029/1999JD900833

[23] Kalapureddy, M.C.R. and Devara, P.C.S. (2010) Pre-Monsoon Aerosol Optical Properties and Spatial Distribution over the Arabian Sea during 2006. Atmospheric Research, 95, 186196. https://doi.org/10.1016/j.atmosres.2009.09.014

[24] Ångström, A. (1961) Techniques of Determining the Turbidity of the Atmosphere. Tellus, 13, 214-223. https://doi.org/10.1111/j.2153-3490.1961.tb00078.x

[25] Junge, C. (1955) The Size Distribution and Aging of Natural Aerosols as Determined from Electrical and Optical Data on the Atmosphere. Journal of Meteorology, 12, 13-25. https://doi.org/10.1175/1520-0469(1955)012<0013:TSDAAO >2.0.CO;2

\section{Submit or recommend next manuscript to SCIRP and we will provide best service} for you:

Accepting pre-submission inquiries through Email, Facebook, LinkedIn, Twitter, etc. A wide selection of journals (inclusive of 9 subjects, more than 200 journals)

Providing 24-hour high-quality service

User-friendly online submission system

Fair and swift peer-review system

Efficient typesetting and proofreading procedure

Display of the result of downloads and visits, as well as the number of cited articles

Maximum dissemination of your research work

Submit your manuscript at: http://papersubmission.scirp.org/

Or contact ojms@scirp.org 